\title{
Fouling Monitoring: Local Thermal Analysis
}

\author{
L. Fillaudeau \\ Laboratory for Biosystems and Process Engineering, French National Institute for Agricultural \\ Research (INRA), Toulouse, France \\ J. Crattelet \\ Laboratory for Biosystems and Process Engineering, Toulouse, and Neosens SA, Labege, France \\ L. Auret \\ Neosens SA, Labege, France
}

\begin{abstract}
In the process industry including agro and bioprocess, fouling is considered to be a complex and misunderstood phenomenon. Heating, holding, and cooling operations are carried out in continuous or batch processes and fouling occurs in equipment with a wide range of kinetics (from minutes up to years) and dimensions (from micrometers up to centimeters). Control and understanding of the fouling phenomenon is of industrial interest as it leads to reduction in process performances, higher energy consumption, and issues with water management. In industrial processes (agri-food, pulp and paper, petrochemistry, etc.), the detection of the fouling level in production lines is a major consideration for optimizing cleaning sequences and their frequency. It is important to have real-time and continuous information about the fouling status of equipment. In heat exchangers, this information is necessary to monitor impaired heat transfers due to deposits (safety and quality of the final product), to prevent biofilm (Legionella risks mitigation) in cooling towers, to reduce costs associated with production, and to optimize chemical discharges which have significant environmental consequences. Various methods, including rheological, chemical, mechanical, optical, ultrasonic, and thermal, have been reported. In this entry, we discuss a fouling sensor that is based on local differential thermal analysis and was developed to study fouling phenomena in batch and continuous processes. First, a bibliographic overview presents similar experimental devices, and theoretical considerations are described. Second, materials and methods are described before presenting our experimental results and a discussion dealing with operating mode, sensor sensitivity to fouling (deposit elimination and formation), and potential applications. The comparison of two operating modes for the sensor-steady (STR) and periodic (PTR) thermal regimes-is also given. Finally, the temperature profile and sensitivity are modeled for the existing sensor geometry.
\end{abstract}

\section{INTRODUCTION}

In the process industry, fouling is considered a complex and misunderstood phenomenon. Heating, holding, and cooling operations are carried out in continuous or batch processes and fouling occurs in equipment with a wide range of kinetics (from minutes up to years) and dimensions (from micrometers up to centimeters). Control and understanding of the fouling phenomenon is of industrial interest $^{[1-22]}$ as it leads to reduction in process performances, higher energy consumption, and issues with water management. Fouling is defined as the deposition of undesirable materials or substances on equipment surfaces (pipes, heat exchangers, etc.). In industrial processes (agri-food and bioprocess, pulp and paper, petrochemistry, etc.), the detection of the fouling level in production lines is a major consideration for optimizing cleaning sequences and their frequency. It is important to have real-time and continuous information about the fouling status of equipment. In heat exchangers, this information is necessary to monitor impaired heat transfers due to deposits, which can affect the quality and purity of the final product, to prevent Legionella risks in cooling towers, to reduce costs associated with production, and to limit emission, which has significant environmental consequences. Various methods, including rheological, chemical, mechanical, optical, ultrasonic, and thermal, have been reported. ${ }^{[9]}$

In this entry, we discuss a fouling sensor that is based on local differential thermal analysis and was developed to study fouling phenomena in batch and continuous processes ${ }^{[6]}$ Potential scientific and industrial applications concern the understanding and control of the fouling nature and mechanism as well as the geometrical design of process equipment under relatively inexpensive investigation 112 
and at a small scale. For instance, the device may be used to analyze deposits (fouling reaction rates) under controlled conditions (bulk and wall temperatures, heat flux, shear stress) and to determine its properties (thermal conductivity and deposit structure and composition) through online and postprocess characterization.

First, a bibliographic overview presents similar experimental devices, and theoretical considerations are described. Second, materials and methods are described before presenting our experimental results and a discussion dealing with operating mode, sensor sensitivity to fouling (deposit elimination and formation), and potential applications. The comparison of two operating modes for the sensor-steady (STR) and periodic (PTR) thermal regimes - is reported. Finally, the temperature profile and sensitivity are modeled for the existing sensor geometry.

\section{BACKGROUND}

Rheological, electrical, chemical, mechanical, optical, sonic, ultrasonic, and thermal methods and the specificities, advantages, and disadvantages of each method have been described in the literature. ${ }^{[22-25]}$ Laboratory and industrial techniques to monitor fouling or product changes are given in Table 1. Several methods have been proposed to monitor fouling in a heat exchanger: 1) the measurement of heat transfer resistance (temperature probe, ${ }^{[3,4]}$ fluxmeter $\left.{ }^{[12,21]}\right)$, 2) the reduction of cross section due to fouling (pressure drop $\left.{ }^{[3,4]}\right)$, 3) the variation of optical properties (turbidimeter ${ }^{[9]}$ diffuse reflectance, ${ }^{[16,17]}$ and backscattered light ${ }^{[26,27]}$ ), electrical methods (electric resistance ${ }^{[28]}$ ), 4) sonic and ultrasonic methods ${ }^{[7,10,13,22]}$ and 5) mass control (weighing of fouled equipment). ${ }^{[4]}$ To sum up, product change and fouling are two different mechanisms that may occur in continuous (flowing fluid) and batch (static fluid) processes under isothermal (holding) or thermal (heating or cooling) conditions. In addition, several factors must be considered with regard to the mechanical design of a sensor: chemical, physical, and thermal resistances; hygienic design and cleanability; as well as limiting factors such as sensitivity and the operating range of the sensor.

Over the past two decades, the hot wire technique has been scrutinized and validated as an accurate method for controlling milk coagulation or the gelation of macromolecular food constituents and several scientific works $^{[1,2,5,11,14,15,19]}$ have been published on this subject. Most of the experimental devices were similar and were

Table 1 Classification of industrial and laboratory techniques to monitor fouling or product changes.

\begin{tabular}{|c|c|c|c|c|c|c|}
\hline Methods/sensors & Level & Process & L/G & In/N-In & OL/PP & Di/Ind \\
\hline \multicolumn{7}{|l|}{ Mechanical methods } \\
\hline Pressure drop & Ind. & $\mathrm{C}$ & G & N-In & OL & Ind \\
\hline Deposit weight & Sc. & $\mathrm{C}$ & G & In & PP & Di \\
\hline \multicolumn{7}{|l|}{ Thermal methods } \\
\hline Temperature gauge & Ind. & $\mathrm{C}$ & G & In & OL & Ind \\
\hline Heat flux sensor & Sc. & $\mathrm{B} / \mathrm{C}$ & $\mathrm{L}$ & N-In & OL & Ind \\
\hline Hot wire method & Sc. & $\mathrm{B} / \mathrm{C}$ & $\mathrm{L}$ & In & OL & Ind \\
\hline Differential thermal analysis & Ind. & $\mathrm{C}$ & $\mathrm{L}$ & In & OL & Ind \\
\hline \multicolumn{7}{|l|}{ Ultrasonic/acoustic methods } \\
\hline $\begin{array}{l}\text { Echoes or sound reflections (ultrasonic frequency } \\
\text { domain reflectometry) }\end{array}$ & Sc. & $\mathrm{C}$ & $\mathrm{L}$ & N-In & OL & Ind \\
\hline Mechanical resonance frequency (piezoelectric crystal) & Sc. & $\mathrm{C}$ & $\mathrm{L}$ & In & OL & Ind \\
\hline \multicolumn{7}{|l|}{ Electrical methods } \\
\hline Electrochemical techniques (redox potential electrodes) & Ind. & $\mathrm{B} / \mathrm{C}$ & $\mathrm{L}$ & In & OL & Ind \\
\hline Electric resistance or conductivity & Sc. & $\mathrm{C}$ & $\mathrm{L}$ & In & OL & Ind \\
\hline Electrical capacitance (dielectric sensor) & Sc. & $\mathrm{C}$ & $\mathrm{L}$ & In & OL & Ind \\
\hline \multicolumn{7}{|l|}{ Optical methods } \\
\hline Light intensity (turbidimeter) & Sc. & $\mathrm{B}$ & $\mathrm{L}$ & N-In & OL & Ind \\
\hline $\begin{array}{l}\text { Emission or absorption method (spectrometry, } \\
\text { bioluminescence, fluorometry) }\end{array}$ & Sc. & $\mathrm{B}$ & $\mathrm{L}$ & N-In & OL & Ind \\
\hline Light reflectance (optic fiber) & Ind. & $\mathrm{B}$ & $\mathrm{L}$ & N-In & OL & Ind \\
\hline
\end{tabular}


employed to monitor or control physical changes during a reaction (gelation, coagulation) in food processes (dairy industry, gel-melting or gel-setting temperatures) even though they are not appropriate for continuous and/or online monitoring of viscosity. ${ }^{[14]}$ However, modified hot wire methods (hot wire with temperature measurement) are in use for determining thermal conductivity of solid food products. ${ }^{[18,20]}$

Industrial devices ${ }^{[1,2,5]}$ are dedicated to process control and an electrical signal issued by the hot wire is used as information. This signal is usually the electrical potential of a platinum wire exposed to a constant direct electric current, whose resistance depends on the temperature and heat dissipation efficiency. Obviously, this limited information may indicate a heat transfer change from natural convection to conduction, but can hardly be used to evaluate or to estimate physical properties (viscosity, thermal conductivity). Dulac ${ }^{[5]}$ reported a thermal sensor consisting of a platinum probe (wire and glass sheath, $L=14 \mathrm{~mm}$, $\varnothing=2 \mathrm{~mm}$ ) and a second temperature gauge used to measure the bulk temperature.

Laboratory devices ${ }^{[11,14]}$ were analyzed from a heat transfer point of view in order to monitor the physical properties of a fluid. The hot wire sensor consisted of a platinum wire $(L=106 \mathrm{~mm}, \varnothing=0.1 \mathrm{~mm})$ immersed axially and in contact with the sample. The authors assumed the surface temperature of the hot wire $\left(\theta_{\mathrm{w}}\right)$ to be equal to the average temperature of the hot wire, whose temperature is calculated from the electric resistance $(R)$. Unfortunately, a hot wire is subject to the Joule effect (a stationary thermal regime with heat generation). Thus, the temperature profile versus radius follows a parabolic curve in a cylindrical wire, even if this is negligible for low power. This assumes more importance when we investigate heat transfer at the interface between the sensor and the product. Free and forced convection heat transfer are described by semiempirical correlations between dimensionless numbers: $N u=f(G r, P r)$ for natural convection and $\mathrm{Nu}=f(\operatorname{Re}, \mathrm{Pr})$ for forced convection. The correlations are restricted to operating conditions and geometrical systems. ${ }^{[8]}$ Dimensionless numbers ( $\left.R e, N u, P r, G r\right)$ require the determination of physical properties (density, viscosity, heat capacity, thermal conductivity) at an accurate temperature (wall, bulk, or film temperature) in order to estimate the heat transfer coefficient with a low precision $( \pm 10-20 \%)$ in specific conditions. The use of a relationship to determine physical properties like viscosity seems inappropriate as the heat transfer mechanism should be perfectly identified (conduction, natural, mixed, or forced convection), an accurate correlation used, and the wall temperature precisely measured.

Passos et al. ${ }^{[15]}$ developed an original system using a heated thermistor instead of a platinum wire in order to increase sensitivity. This thermistor (heated wire, $\varnothing=0.08$ $\mathrm{mm})$ was placed in a hypodermic needle $(L=30 \mathrm{~mm}$, $\varnothing=0.55 \mathrm{~mm})$ and its voltage drop indicated product change. In addition, a type $\mathrm{T}$ thermocouple was in contact with the hot wire inside the needle. This sensor was validated to monitor thermal conductivity during milk coagulation.

Reported publications provide the following information:

- No direct measurement of the wall temperature at the fluid-product interface has been carried out till date.

- Investigations have been limited to static fluids (batch process) under isothermal conditions.

- Most of the applications concern dairy products.

Furthermore, we note that the hot wire method is mainly used for thermal conductivity measurements in solid food products; investigations have not been undertaken to monitor fouling in continuous and thermal processes.

\section{MATERIALS AND METHODS}

\section{Thermal Sensor and Measuring System}

The concept of the experimental device came from two specific food applications: 1) the use of the hot wire method to monitor milk coagulation under static and isothermal conditions $^{[1,2,5,11,15]}$ and 2) the wall temperature measurement in tubular Joule effect heaters (JEH) to quantify the heat transfer coefficient and fouling mechanism in a continuous heating process. The thermal sensors were made of two platinum probes (1-Sté Heraeus, probe UE go2327, class $\mathrm{B}, L=25 \mathrm{~mm}, \varnothing=3 \mathrm{~mm}$ or 2-Sté Heraeus, probe DS2-Pt16-X-Cu2-12S-MMCU, $L=30 \mathrm{~mm}, \varnothing=1.6 \mathrm{~mm}$ ) and one thermocouple (1-Sté Thermo-Electric, Type K, ref. MTS-56025-2500-1500, $\varnothing=250 \mu \mathrm{m}$ or 2-Sté Coram, probe type K, ref. DC2-Ko25L-1000i, $\varnothing=250 \mu \mathrm{m}$ ).

One platinum probe acted as a sheathed hot wire sensor. A platinum wire with ceramic and stainless-steel sheaths was used, as shown in Fig. 1. The ceramic sheath ensured the electrical insulation between the stainless steel and the platinum wire. The platinum wire (hot wire) was connected to a direct current generator $(0-50 \mathrm{~mA})$. The electric current $(I)$ and potential $(U)$ applied to the standard resistance were recorded and the heat power $(P, 0-250 \mathrm{~mW})$, the flux $\left(\varphi, 0-2 \mathrm{~kW} \mathrm{~m}^{-2}\right)$, and the electric resistance $(R)$ calculated. The electric resistance enabled us to determine the average temperature of the platinum hot wire, based on the relationship between $\theta$ and $R$ for a standard platinum probe (Eq. $1 ; R_{0}, A$, and $B$ are constants).

$R=R_{0}\left(1+A \cdot \theta+B \cdot \theta^{2}\right)$

The thermocouple was stuck halfway along the platinum probe and measured the wall temperature $\left(\theta_{\mathrm{w}}\right)$ at the sensor-product or sensor-deposit interface. The second platinum probe measured the bulk temperature $\left(\theta_{\mathrm{b}}\right)$.

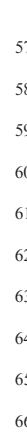




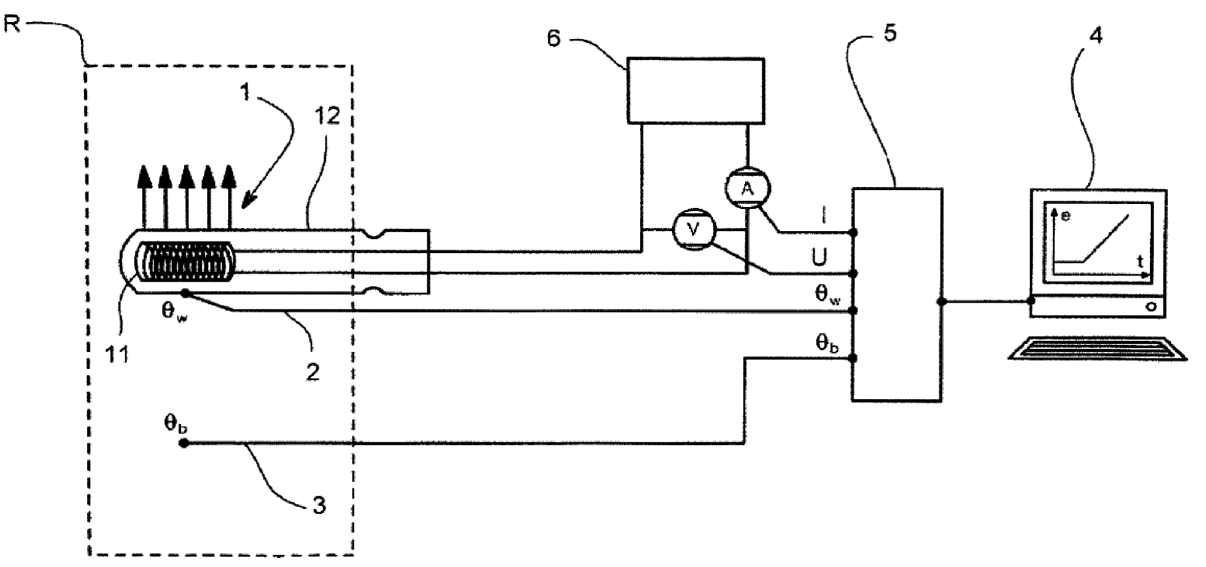

Fig. 1 Thermal sensor structure and sensitive interface with deposit or product (INRA patent no. FR2885694).
Each sensor signal $\left(I, U, \theta_{\mathrm{w}}, \theta_{\mathrm{b}}\right)$ was converted using a specific conversion card (Sté Analog Device, module 6B) and recorded on a computer (PC type 386) with specific acquisition software. After calibration and as per experimental conditions, the expected precisions were as follows: for temperature, $\pm 0.5^{\circ} \mathrm{C}$, for electric current, $\pm 0.1 \%$, and for potential, $\pm 0.1 \%$.

\section{Theoretical Considerations}

It is assumed that there is heat generation inside the sensor (flat or cylindrical shapes). In the platinum probe, we consider the heat transfer balance (Eq. 1) in cylindrical coordinates:

$\frac{1}{a} \cdot \frac{\mathrm{d} \theta}{\mathrm{d} t}=\nabla \theta+q \quad$ with $\quad a=\frac{\lambda}{\rho \cdot C}$

Geometric and thermal simplifications lead to the simplification of this formula in the platinum wire submitted to the Joule effect (heat generation and heat conduction) and in the sheath (heat conduction) in contact with the deposit or fluid. A fouling sensor may be used under various thermal modes as reported in Table 2. Taking into consideration the sheath surrounding the heat source and in contact with the fluid/deposit, initial and boundary conditions could be formulated for one-dimensional (flat and radial coordinates) analysis. Heat transfer balance can be solved and temperatures versus position and time could be established. In our case, steady and periodic (sinusoidal heat flux generation) thermal regimes were investigated.

\section{Steady thermal regime}

Geometric and thermal simplifications lead to the simplification of this formula in the platinum wire submitted to the Joule effect and in the ceramic and stainless-steel sheaths. We made the following assumptions:

- Permanent thermal regime, $\mathrm{d} \theta / \mathrm{d} t=0$.

- Heat generation was limited to the platinum hot wire, $q \neq 0$.

- In the central cylinder (ceramic), flux was equal to zero, $\varphi=0$.

- Geometric simplification with $L>>r$.
Table 2 Initial and boundary conditions to solve heat conduction equation under working conditions of fouling sensors.

\begin{tabular}{|c|c|c|c|}
\hline & & Initial conditions & Boundary conditions \\
\hline \multirow[t]{2}{*}{ Constant heat flux } & Steady thermal regime & & $\begin{array}{l}\theta(0)=\theta_{w} \\
\theta\left(e_{\text {sheath }}+e_{\mathrm{d}}\right)=\theta_{\mathrm{b}}=C t e \\
\varphi(0)=\varphi_{0}=C t e\end{array}$ \\
\hline & Transient thermal regime & $\begin{array}{l}\theta(x, 0)=\theta_{\mathrm{b}} \text { for } t<0 \\
\theta\left(e_{\text {sheath }}+e_{\mathrm{d}}\right)=\theta_{\mathrm{b}}=C t e \\
\varphi(x, 0)=0 \text { for } t<0 \\
\varphi(0, t)=\varphi_{0} \text { for } t \geq 0\end{array}$ & $\begin{array}{l}\theta(0, t)=\theta_{\mathrm{w}} \\
\theta\left(e_{\text {sheath }}+e_{\mathrm{d}}\right)=\theta_{\mathrm{b}}=C t e \\
\varphi(0)=\varphi_{0}=C t e\end{array}$ \\
\hline \multirow[t]{2}{*}{$\begin{array}{l}\text { Periodic (sinusoidal) heat } \\
\text { flux }\end{array}$} & Steady periodic thermal regime & & $\begin{array}{l}\theta(0, t)=\theta_{\mathrm{w}}(t) \\
\theta\left(e_{\text {sheath }}+e_{\mathrm{d}}, t\right)=\theta_{\mathrm{b}}=C t e \\
\varphi(0, t)=\varphi_{0} \cdot(1+\cos (\omega \cdot t))\end{array}$ \\
\hline & $\begin{array}{l}\text { Transient periodic thermal } \\
\text { regime }\end{array}$ & $\begin{array}{l}\theta(x, 0)=\theta_{\mathrm{b}} \text { for } t<0 \\
\theta\left(e_{\text {sheath }}+e_{\mathrm{d}}\right)=\theta_{\mathrm{b}}=C t e \\
\varphi(x, 0)=0 \text { for } t<0 \\
\varphi(0, t)=\varphi_{0} \cdot(1+\cos (\omega \cdot t)) \text { for } t \geq 0\end{array}$ & $\begin{array}{l}\theta(0, t)=\theta_{\mathrm{w}}(t) \\
\theta\left(e_{\text {sheath }}+e_{\mathrm{d}}, t\right)=\theta_{\mathrm{b}}=C t e \\
\varphi(0, t)=\varphi_{0} \cdot(1+\cos (\omega \cdot t))\end{array}$ \\
\hline
\end{tabular}


$01 \quad$ Flux and power were determined based on geometrical 02 dimensions and electrical parameters $(I, U)$. Heat transfer 03 may be formulated for a constant flux (Eqs. 3 and 4), and in

a system in which a deposit layer may exist.

$P=K^{\prime} \cdot 2 \cdot \pi \cdot L \cdot\left(\theta_{\mathrm{w}}-\theta_{\mathrm{b}}\right)$

with

$$
\frac{1}{K^{\prime}}=\frac{1}{h \cdot(r+e)}+\frac{\ln \left(1+\frac{e}{r}\right)}{\lambda_{\mathrm{d}}}
$$

The temperature difference between wall and bulk, $\Delta \theta$, is formulated (Eq. 5):

$\Delta \theta=\theta_{\mathrm{w}}-\theta_{\mathrm{b}}=\frac{P}{2 \pi L}\left(\frac{1}{h(r+e)}+\frac{\ln \left(1+\frac{e}{r}\right)}{\lambda_{\mathrm{d}}}\right)$

Under clean conditions, a moderate heat flux (0.1-0.7 $\mathrm{kW} \mathrm{m}^{-2}$ ) and permanent flow regime is applied. In this condition, we assume a thermally and hydrodynamically developing flow around an immersed body (plate, cylinder), ${ }^{[8]}$ and then the heat transfer coefficient, $h$, reaches an important value $\left(>1000 \mathrm{~W} \mathrm{~m}^{-2} \mathrm{~K}^{-1}\right)$, which induces the temperature difference between wall and bulk tends toward $0^{+}$(in agreement with the temperature gauge's precision). This criterion appears fundamental because wall overheating may induce fouling and should be avoided. During product processing, we assume that fouling phenomena are homogeneous, and detection and quantification of the deposit becomes feasible. From Eq. 5, we understand that the geometry of the active sensor yields different " $\Delta \theta-$ Time" curves based on deposit evolution.

In addition, the electric current passing through the hot wire defines the heat generated as well as the working area of the thermal sensor. For low electric current (1-5 mA), it corresponds to the conventional use of a temperature gauge (Pt100) for temperature measurement. For high electric current (above $50 \mathrm{~mA}$ ), the hot wire is used as a heat generator. For intermediate electric current $(5-50 \mathrm{~mA})$ and under appropriate thermal and hydraulic conditions, the sensor could be used to monitor fouling phenomena.

We note that $\Delta \theta$, equal to $\left(\theta_{\mathrm{w}}-\theta_{\mathrm{b}}\right)$, is a consequence of the flux and global heat transfer coefficient $(K)$. At constant flux, if the product structure evolves (fusion, gelation, cooking) or a deposit layer increases or disappears (fouling, cleaning), then the global heat transfer coefficient changes along with $\Delta \theta$. Thus, if our knowledge of the product is reliable, heat transfer analysis (conduction, convection) may lead to interesting information about product changes or process fouling. An overview of the heat transfer in the probe and the product leads to a calculation of the temperature profile versus the radius in permanent regime.

\section{Periodic thermal regime}

In the solid-state field, the periodic temperature field is used to measure thermal conductivity. A periodic heat flux applied at the outer surface induces a periodic temperature throughout the whole cylinder or wall. After the initial transient phase, a damped temperature signal, with a damping factor that depends on the frequency, is obtained away from the heat flux source. Therefore, the frequency can be adjusted so that a detectable temperature signal at a certain position in the cylinder or the wall can be recorded by a temperature sensor. ${ }^{[29]}$

The periodic change in temperature of the surroundings may be represented by a simple harmonic oscillation. The phase lag and amplitude of the periodic temperature response are functions of the normalized position, the Biot number, and a reciprocal Fourier number as the characteristic time. The amplitude is a function of the Fourier number, which is a function of thermal diffusivity. ${ }^{[29-32]}$

In this case, the thermal regime is not permanent, $\mathrm{d} \theta / \mathrm{d} t \neq 0$, and heat flux is generated in agreement with a defined sinusoidal signal. A thermocouple, $T_{\mathrm{w}}$, is used to measure the temperature variation at the sensor-product or sensor-deposit interface. Heat flux is modulated with a known frequency $(\omega=2 \pi f)$ and amplitude $\left(\varphi_{0}\right)$. A specific software using Fast Fourier Transform (FFT) enables online signal treatment. Using Eq. 6, the amplitude and the phase of a signal at a given frequency can be calculated. Thus, the thermal amplitude of wall temperature $\left(\theta_{\mathrm{w}}\right)$ and the phase lag between $\theta_{\mathrm{w}}$ and heat flux $(P)$ are calculated.

$$
\begin{aligned}
\forall k & \in[0, N-1], X_{n}[k] \\
& =\sum_{n=0}^{N-1} x[n] \times \exp \left(\frac{-j \cdot 2 \cdot \pi \cdot k \cdot n}{N}\right)
\end{aligned}
$$

\section{Experimental Device and Protocol}

\section{At the laboratory scale}

For batch processes, the experimental device consisted of a water bath equipped with a thermal regulator and a stirrer. The sample was immersed in the water bath and could be stirred with a magnetic stirrer in order to simulate a fluid in motion (turbulent regime). The thermal sensors were plunged vertically into the test fluid and a thermal insulator was placed at the top to avoid thermal heat loss. A turbulent flow regime was ensured by fluid circulation and mixing surrounding fouling sensor.

A model deposit was simulated by using wax layers of different thicknesses. Wax provides the advantages of being easily shaped around the sensor, of fusing at $57^{\circ} \mathrm{C}$, simulating a deposit layer elimination with rising temperature, and of exhibiting a low thermal conductivity $\left(\lambda=0.1 \mathrm{~W} \mathrm{~m}^{-1} \mathrm{~K}^{-1}\right)$. 
Experiments were conducted using wax layers of different thicknesses $(0-4 \mathrm{~mm})$ and moderate heat power $(0-250 \mathrm{~mW}$ equivalent to heat flux inferior to $2000 \mathrm{~W} \mathrm{~m}^{-2}$ ) was dissipated.

\section{At the pilot-plant scale}

For continuous processes, fouling experiments were carried out at the pilot-plant scale with two cylindrical sensors (sensor 1: $L=30 \mathrm{~mm}, \varnothing=1.6 \mathrm{~mm}$; sensor 2: $L=15 \mathrm{~mm}$, $\varnothing=2.5 \mathrm{~mm}$ ) installed within a simple geometry flow section. The devices were placed at the center of a duct $(\varnothing=1 \mathrm{inch})$ and were perpendicular to the main flow direction. This system was installed at the inlet of the holding section (just after the heater) to monitor fouling. In the active phase, the same heat flux density was dissipated by both sensors.

The design and conception of the pilot enabled heat treatment to be carried out with a large degree of autonomy (electric power control, temperature regulation, and fluid flow). The pilot plant included three storage tanks $\left(1 \mathrm{~m}^{3}\right)$ : product, water for start-up and stopping phases, and a cleaning solution. A displacement pump ensured feeding of a series of heat exchangers. The experimental setup consisted of four different sections: 1) the preheating zone (PHE, type V7, 7pass, 1c/p); 2) the heating zone (PHE, type V7, 7pass, 1c/p); 3) the holding zone (smooth tube, $D=23 / 25, L=3 \mathrm{~m}$ ); and 4) the cooling zone (THE, Actitube, 12 tubes, $D=23 / 25, L=1.30 \mathrm{~m}$ ). The product was stored at $T_{0}=4^{\circ} \mathrm{C}$, preheated at $T_{1}=60^{\circ} \mathrm{C}$, and heated in the first two plate heat exchangers to reach $T_{2}=105^{\circ} \mathrm{C}$. The holding chamber (tube, diameter: $23 / 25$ and $L=3 \mathrm{~m}$ ) at $T_{3}=105^{\circ} \mathrm{C}$ is the area under study. Finally, the product was cooled up to $T_{4}=20^{\circ} \mathrm{C}$ in a tubular heat exchanger. Experimental measurements were flow rate, temperature, relative and differential pressure, electrical conductivity, and fouling sensor signals.

The experimental product was a fouling model fluid to simulate rheological behavior and fouling propensity. It consisted of $\beta$-lactoglobulin ( $1 \% \mathrm{w} / \mathrm{w})$, which generates a protein deposit with a mean thermal conductivity of $0.27 \mathrm{~W} \mathrm{~m}^{-1} \mathrm{~K}^{-1}$. During run, the flow rate was $400 \mathrm{~L} / \mathrm{hr}$ for a fouling period of $2 \mathrm{hr}$ (Table 1). The start-up phase used water to reach stable thermal and hydrodynamic parameters. After the fouling phase, the heat exchanger was dismantled to observe the deposit inside the tube and at the sensor surface. In this condition, a type A deposit is mainly generated and we assume that its equivalent thermal conductivity is $0.27 \mathrm{~W} \mathrm{~m} \mathrm{~m}^{-1} \mathrm{~K}^{-1}$ as demonstrated by Delplace. $^{[4]}$ Finally, a cleaning-in-place (CIP) procedure with caustic agent $(\mathrm{NaOH} 2 \%$ w/w) was done ( $\left.Q=400 \mathrm{~L} / \mathrm{hr}, T=80^{\circ} \mathrm{C}\right)$.

Experimental parameters recorded and exploited were the reduced hydrodynamic or thermal criteria. The reduced pressure drop, $\mathrm{DP} / \mathrm{DP}_{0}(/)$, and relative inlet pressure, $P R$ $(/)$, were analyzed. In the meantime, the heat transfer resistance, $R_{\mathrm{f}}$, or reduced heat transfer, $R_{\mathrm{h}}$, was calculated and compared with fouling sensor parameters ( $\Delta \theta=\theta_{\mathrm{w}}-\theta_{\mathrm{b}}$ or thermal amplitude or $1 /(K S)$ or phase lag).

$$
\begin{aligned}
& \frac{2 e_{\mathrm{d}-\mathrm{hyd}}}{D_{\mathrm{h}_{0}}}=\frac{D_{\mathrm{h}_{0}}-D_{\mathrm{h}}}{D_{\mathrm{h}_{0}}}=1-\left(\frac{\mathrm{DP}_{0}}{\mathrm{DP}}\right)^{\frac{1}{3}} \\
& R_{\mathrm{h}}=\frac{1}{\left(\frac{K}{K_{0}}\right)} ; \quad R_{\mathrm{f}}=\frac{1}{K}-\frac{1}{K_{0}}
\end{aligned}
$$

\section{RESULTS AND DISCUSSION}

\section{Sensitivity to Fouling under Steady and Periodic Thermal Flux (Laboratory Scale)}

Fouling control in continuous food processes is a fundamental parameter. Fouling may occur in heaters (compound denaturation, hot surface) or coolers (gelation or solidification at wall) and even in holding sections (product maturation). Sensor sensitivity was investigated with the two methods for the same thermal resistance, $R_{\mathrm{th}}=e / \lambda_{\mathrm{d}}$, and thermal diffusivity, $a$, versus heat flux density and frequency. Fig. 2 illustrates raw data obtained with steady and periodic heat flux. The first time, the sensor works in STR and thus we calculated $\Delta \theta=\theta_{\mathrm{w}}-\theta_{\mathrm{b}}$ for a constant flux $(P=100 \mathrm{~mW})$. Next, for the PTR, heat flux was modulated and we recorded the amplitude of wall temperature and phase lag between $\theta_{\mathrm{w}}$ and the flux generated. Bulk temperature remains constant during these experiments.

The evolution of thermal amplitude with thermal resistance shows the increase in amplitude with the increase in thermal resistance (Fig. 3) and the decrease in thermal amplitude with the increase in frequency (Fig. 4) for the same thermal resistance. In the absence of deposits, thermal regime does not have any impact. But in other cases, an optimal frequency for each thermal resistance to calculate thermal amplitude near to $\Delta \theta$ measured in STR and not to loose information. In this case, thermal diffusivity should be considered in order to take into account the specific heat capacity and thermal conductivity of the deposit.

The optimal frequency is related to the response time $\left(t_{90 \%}\right)$ of fouled sensor. Values could be estimated from classical solutions of second Fourier's law giving dimensionless temperature versus dimensionless time (Fourier number) and Biot number.

If there is no deposit on the sensor, $\Delta \theta$ is close to zero when the flux density increases in both regimes. With a defined thermal resistance, the increase of $\Delta \theta$ or thermal amplitude is linear with flux density increase. Moreover, it is important to note that even if the thermal amplitude, under PTR, increases, there is a difference under STR. It is due to the frequency used $(f=0.0125 \mathrm{~Hz})$, which is not appropriate for such a thermal resistance. 


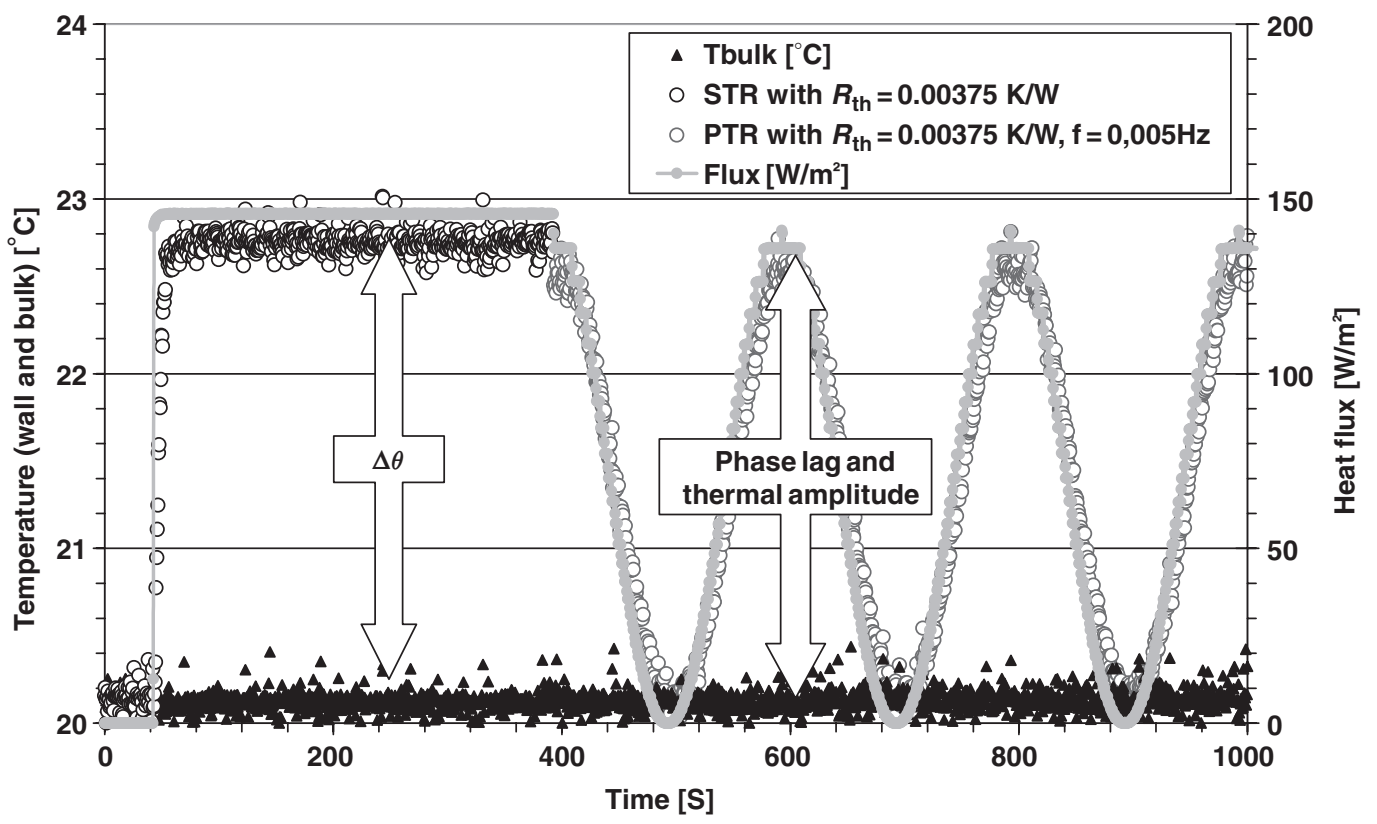

Fig. 2 Evolution of experimental parameters (flux, wall and bulk temperature) under steady and periodic thermal regime (i.e., $P=100 \mathrm{~mW}$, $e=0.4 \mathrm{~mm}$ ).
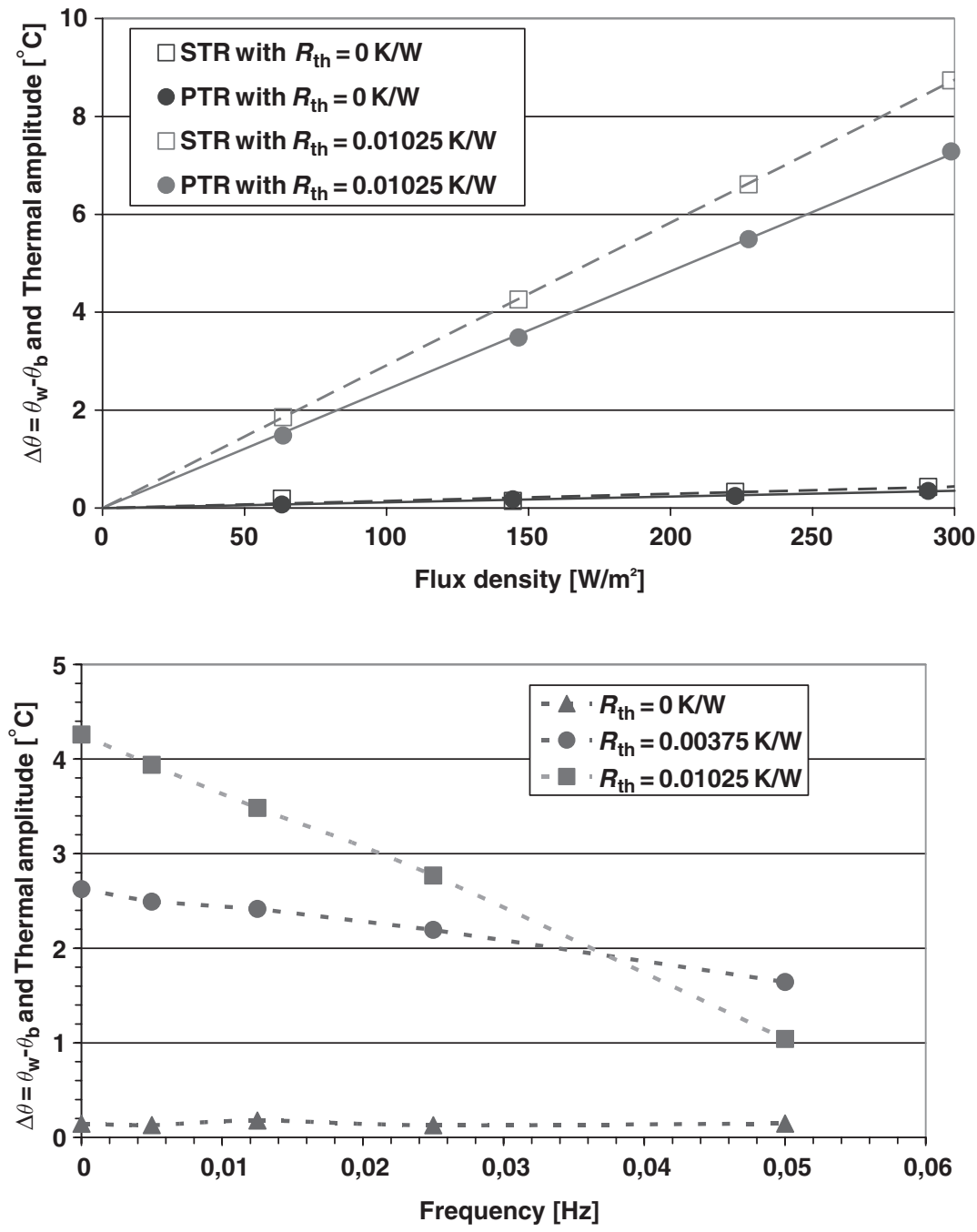

Fig. 3 Evolution of $\Delta \Theta$ (STR) and thermal amplitude (PTR, $f=0.0125 \mathrm{~Hz}$ ) versus flux density $\left(\mathrm{W} \mathrm{m}^{-2}\right)$ under clean $(e=0 \mathrm{~mm})$ and fouled $(e=1 \mathrm{~mm})$ conditions.
Fig. 4 Evolution of $\Delta \Theta$ (STR) and thermal amplitude (PTR) versus frequency $(\mathrm{Hz})$ at $P=100 \mathrm{~mW}$. 


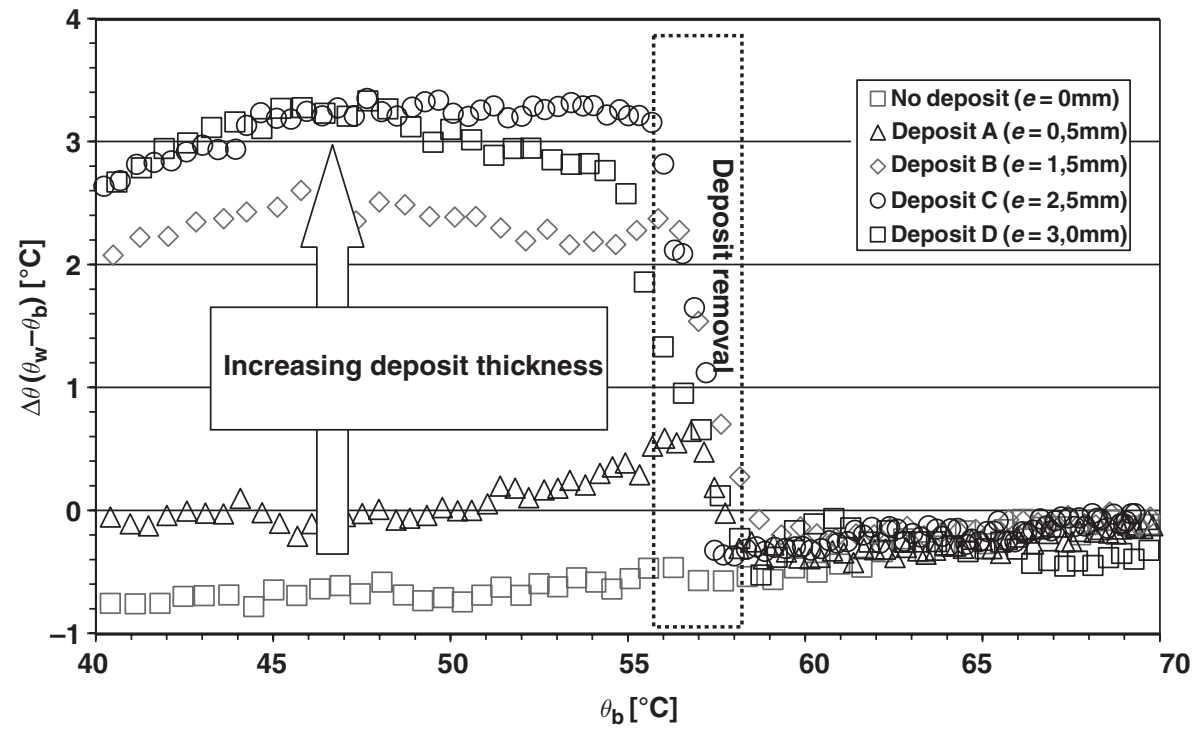

Fig. 5 Temperature difference $(\Delta \Theta)$ versus bulk temperature $\left(T_{\mathrm{b}}\right)$ impact of deposit layer and sensitivity to fouling elimination.
The decrease in thermal amplitude with frequency (Fig. 4) shows the stability of the amplitude for a thermal resistance equal to zero. When there is a deposit on the sensor, it is necessary to use a frequency that is as low as possible to prevent a decrease in the thermal amplitude measured.

Finally, the sensor sensitivities to deposit thickness and elimination were evaluated under STR. Fouling layers were created at the sensor surface and the temperature difference versus bulk temperature was monitored when the sensor was immersed in stirred water (Fig. 5). For bulk temperatures below the fusion temperature of wax $\left(57^{\circ} \mathrm{C}\right)$, we observed an increase in the temperature difference with an increase in the deposit thickness. As per Eqs. 4 and 5, the temperature difference should become constant when deposit thickness increases. This point was experimentally observed and explained by the asymptotic value of the global heat transfer coefficient when the deposit increased (Eq. 5). At temperatures exceeding $55^{\circ} \mathrm{C}$, deposit elimination was monitored without any problem. For temperatures above $60^{\circ} \mathrm{C}$, a complete removal of the deposit was seen and the temperature differences reached a common value close to zero.

\section{Fouling Monitoring in Continuous Process (Pilot Plant)}

In continuous processes, the thermal sensor should enable one to get an insight into fouling propensity in the process. $^{[33,34]}$ In STR, the temperature difference $(\Delta \theta)$ recorded by the thermal sensor is considered as the main indicator, which is in agreement with Eq. 5 (cylindrical geometry). We followed fouling in a holding section, for which little or no data are available. However, holding remains one of the most important operations in continuous processes in order to ensure cooking, maturation, and sterilization of the product, even though fouling also occurs in the heat exchanger.

The fouling thermal sensor, used as a local deposit sensor, was compared to conventional global techniques

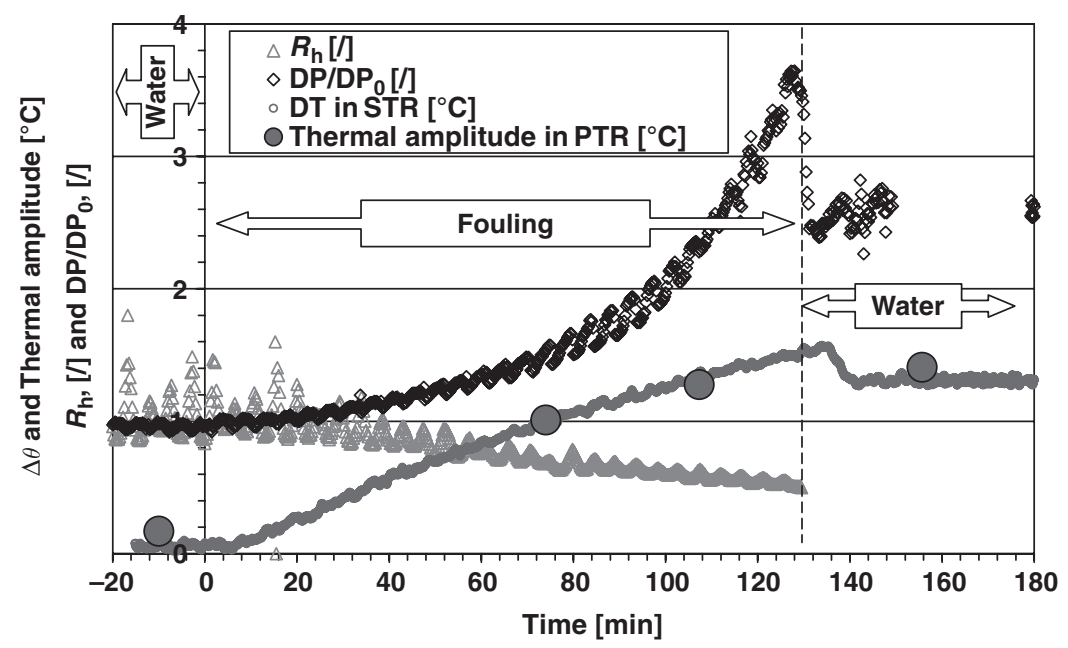

Fig. 6 Evolution of fouling criteria $\Delta \Theta$ (in STR), thermal amplitude (in PTR), and global process criteria $\left(\mathrm{DP} / \mathrm{DP}_{0}\right.$ and $\left.R_{\mathrm{h}}\right)$ during heat treatment of a dairy model fluid. 


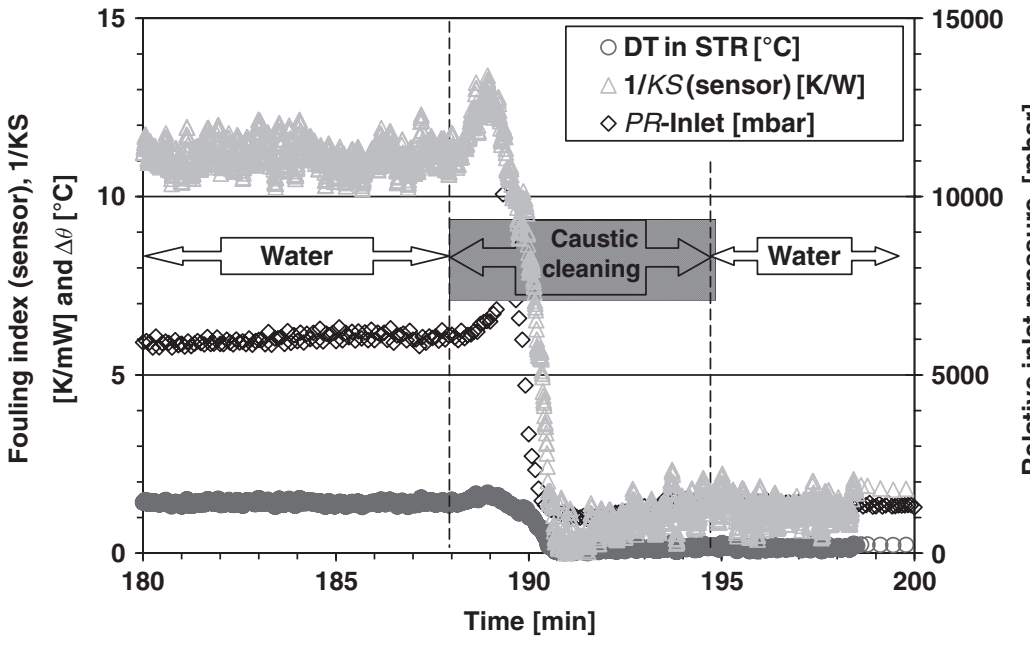

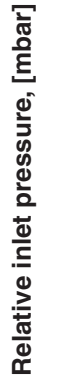

Fig. 7 Evolution of fouling criteria $\Delta \Theta$ (in STR), local fouling index $1 / K S$ (sensor), and inlet relative pressure $P R$ during cleaning-in-place with a caustic agent. (pressure drop, overall heat transfer coefficient) and validated as an accurate method. Figs. 6 and 7 represent the monitoring of fouling and cleaning phases, respectively. For the fouling phase, we lay stress on the increase in the values of sensor data- $\Delta \theta$ and thermal amplitude-under STR and PTR, respectively. The two methods are correlated and enable the monitoring of the fouling phase. Global measurements $\left(R_{\mathrm{h}}, \mathrm{DP} / \mathrm{DP}_{0}\right)$ confirm the deposit increase during the process, in agreement with fouling sensor parameters. After the fouling phase, the stabilization of data under water rinsing is observed. Monitoring of CIP is shown in Fig. 7. Data recorded from the sensor $(\Delta \theta$ and fouling index $1 / K S=\Delta \theta / P$ ) show a return to the baseline after caustic cleaning. Relative pressure follows the same trend and correlates sensor data.
The sensor exhibits a low thermal inertia, an accurate sensitivity to fouling phenomena, and is easily implemented in the process. However, its use should satisfy several criteria like the shape, dimensions, mechanical and chemical resistance, the control of generated heat flux, and thermal and hydraulic conditions. The comparison of two working regimes, STR and PTR, shows that it is important to know, for the measurement of a given thermal resistance, the optimal frequency in the periodic regime. In PTR, the thermal diffusivity should be carefully considered to integrate specific heat capacity and thermal conductivity of the deposit. There are different advantages to using such a working mode: two distinct parametersthermal amplitude and shift between two signals $\left(P, \theta_{\mathrm{w}}\right)$ could be obtained and surface overheating was modulated.

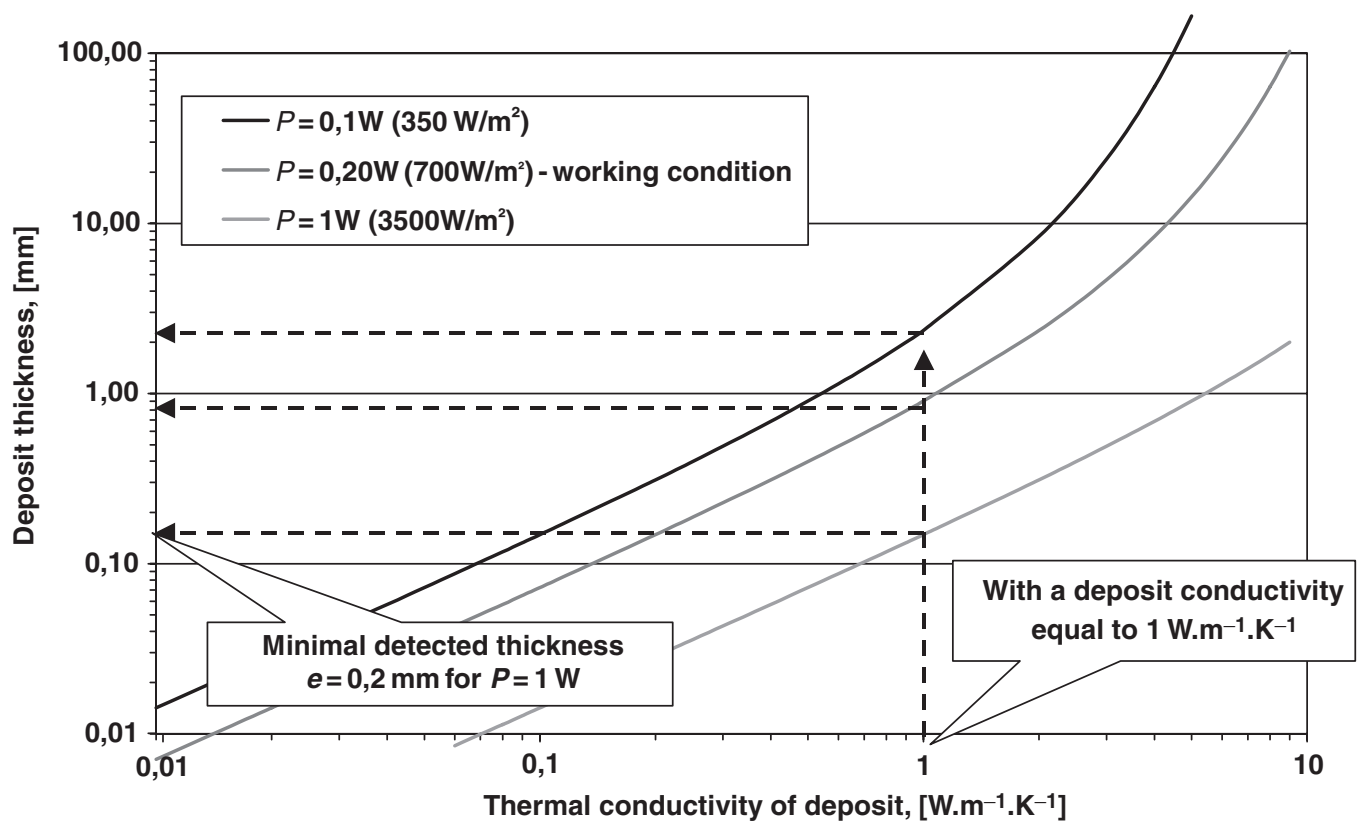

Fig. 8 Minimal deposit quantified $(e)$ versus deposit thermal conductivity, $\lambda_{\mathrm{d}}$, and heat power, $P$ (and flux) for $\Delta \Theta$ step of $+0.5^{\circ} \mathrm{C}$ (sensor radius: $1.5 \mathrm{~mm}$ and length: $30 \mathrm{~mm}$ ). 


\section{Detection Limits}

Finally, we focused on the limits of fouling detection for the thermal sensor. We considered Fourier's law for an annular cylinder. Internal $\left(\theta_{\mathrm{w}}\right)$ and external $\left(\theta_{\mathrm{b}}\right)$ temperatures were controlled, and a heat flux was imposed. Our system was limited by wall and bulk temperature precision $\left( \pm 0.5^{\circ} \mathrm{C}\right)$ and we assumed a variation of $0.5^{\circ} \mathrm{C}$ as the minimal temperature difference required to detect a significant deposit. In Fig. 8, the minimal deposit quantified is plotted against the thermal conductivity of the deposit and heat power. We observed that in our experimental conditions (sensor geometry, heat power equal to $0.20 \mathrm{~W}$ ) for food products (thermal conductivity ranging between 0.1 and $0.6 \mathrm{~W} \mathrm{~m}^{-1} \mathrm{~K}^{-1}$ ), the thermal sensor may detect a fouling $0.1-0.5 \mathrm{~mm}$ in thickness.

\section{CONCLUSIONS}

Fouling detection and quantification in food process equipment constitutes real practical interest. Over the past few decades, several sensors were investigated to monitor and control fouling, as reported. In this study, a thermal sensor using differential thermal analysis under steady and periodic heat flux has been scrutinized and validated as an accurate device to investigate fouling phenomena or product changes in batch and continuous food processes. ${ }^{[6]}$ Experimental investigation and theoretical analysis of heat transfer highlight its potential application in food processes as well as its accuracy in evaluating deposit properties. The sensor exhibits a low thermal inertia and an accurate sensitivity to fouling phenomenon, and is easily implemented in the process. However, its use should satisfy several criteria like shape, dimensions, mechanical and chemical resistance, the control of generated heat flux, and thermal and hydraulic conditions.

For scientific purposes, the experimental device may be used to analyze and understand fouling phenomena (fouling reaction rates) versus controlled conditions (bulk and wall temperature, heat flux, shear stress) and to determine properties of deposits (thermal conductivity, fouling kinetics, deposit structure, and composition) through online or postprocess analyses at the laboratory scale.

For industrial purposes, the device can be installed at different locations along an industrial line in order to analyze deposits but it can also constitute an interesting tool to improve the mechanical design and flow requirements of process equipment (temperature gauge structure, flow distribution, surface nature).

\section{NOMENCLATURE}

\section{Latin Letters}

$a \quad$ Thermal diffusivity $\left(\mathrm{m}^{2} \mathrm{sec}^{-1}\right)$

$A, B$ Constant
C Heat capacity $\left(\mathrm{J} \mathrm{K}^{-1} \mathrm{~kg}^{-1}\right)$

$D_{\mathrm{h}} \quad$ Hydraulic diameter $(\mathrm{m})$

DP Pressure drop $(\mathrm{Pa})$

$e \quad$ Thickness of deposit (m)

$f \quad$ Frequency $(\mathrm{Hz})$

Gr Grashoff number (/)

$h \quad$ Convection heat transfer $\left(\mathrm{W} \mathrm{m}^{-2} \mathrm{~K}^{-1}\right)$

I Electric current (A)

$K \quad$ Overall heat transfer coefficient $\left(\mathrm{W} \mathrm{m}^{-2} \mathrm{~K}^{-1}\right)$

$K^{\prime} \quad$ Heat transfer coefficient (sensor) $\left(\mathrm{W} \mathrm{m}^{-1} \mathrm{~K}^{-1}\right)$

$L \quad$ Length (m)

$\mathrm{Nu} \quad$ Nusselt number (/)

$P \quad$ Heat power $(\mathrm{W})$

Pr Prandtl number (/)

$q \quad$ Volume heat generation $\left(\mathrm{W} \mathrm{m}^{-3}\right)$

$r \quad$ Radius sensor $(\mathrm{m})$

$R \quad$ Electric resistance $(\Omega)$

Re Reynolds number $(/)$

$R_{\mathrm{h}} \quad$ Heat transfer resistance (/)

$R_{\mathrm{f}} \quad$ Reduced heat transfer $\left(\mathrm{m} \mathrm{K} \mathrm{W}^{-1}\right)$

$R_{\mathrm{th}} \quad$ Deposit thermal resistance $\left(\mathrm{W} \mathrm{m} \mathrm{m}^{-1} \mathrm{~K}^{-1}\right)$

$t \quad$ Time (sec)

$U \quad$ Potential (V)

X Variable

\section{Greek Letters}

$\begin{array}{ll}\alpha & \text { Angle }(\mathrm{rad}) \\ \varphi & \text { Flux }\left(\mathrm{W} \mathrm{m}^{-2}\right) \\ \lambda & \text { Thermal conductivity }\left(\mathrm{W} \mathrm{m}^{-1} \mathrm{~K}^{-1}\right) \\ \theta & \text { Temperature }\left({ }^{\circ} \mathrm{C}\right) \\ \rho & \text { Volume mass }\left(\mathrm{kg} \mathrm{m}^{-3}\right) \\ \Delta \theta & \text { Temperature difference }(\mathrm{K})\end{array}$

\section{Indices}

$\begin{array}{ll}\text { 0 } & \text { Initial } \\ \mathrm{b} & \text { Bulk } \\ \mathrm{d} & \text { Deposit } \\ \mathrm{w} & \text { Wall }\end{array}$

\section{REFERENCES}

1. Auvergne, A.; Lekhal, D.; Surel O.; Bayourthe C. Utilisation d'un coagulometre à fil chaud en technologie fermière. Industries Alimentaires Agricoles 2002, Juillet-Aout, 9-13.

2. Bellon, J.L.; Quiblier, J.P.; Durier, Ch.; Noel, Y. Un nouveau capteur industriel de mesure du temps de coagulation du lait. Technique laitière 1988, 1031, 29-32.

3. Corrieu, G.; Lalande, M.; Ferret, R. Mesure en ligne de l'encrassement et du nettoyage d'un stérilisateur UHT industriel. J. Food Eng. 1986, 5, 231-248.

4. Delplace, F. Identification des echangeurs de chaleur à plaques-application à l'étude de l'encrassement par les produits laitiers. Ph.D. thesis, Université de Nancy I, 1995. 
5. Dulac, A. Etude de la réponse d'une méthode thermique pour suivre la coagulation du lait, Ph.D. thesis, Université de Compiègne, 1990.

6. Fillaudeau, L.; Cardenas, R.; Korolzuck, J.; Lejaye, J.; Cozic, F.; Debreyne, P. Application of the hot wire method to monitor fouling phenomena in food process. In Proceedings of ICEF-9, Montpellier (France), March 7-11, 2004, 195-200.

7. Gunasekaran, S.; Ay, C. Milk coagulation cut-time determination using ultrasonics, J. Food Process Eng. 1996, 19 (1), 63-73.

8. Gnielinski, V.; Churchill, S.W. Single phase convective heat transfer. In Heat Exchanger Design Handbook; ISBN 0-89116-125-2; Brienza, B.M., Gandy, J.B., Lackenback, L., Eds.; Hemisphere Publishing Corporation: Washington D.C., 1993; Vol. 2.

9. Hardy, J.; Fanni, J.; Scher, J. Une méthode turbidimétrique de mesure de la coagulation du lait. Revue laitière Française 1985, 441, 13-18.

10. Hay, T.R.; Rose, J.L. Fouling detection in the food industry using ultrasonic guided waves. Food Control 2003, 14, 481-488.

11. Hori, T. Objective measurements of the process of curd formation during rennet treatment of milks by the hot wire method. J. Food Sci. 1985, 50, 911-917.

12. Jones, A.D.; Ward, N.J.; Schreier, P.J.R.; Fryer, P.J. The use of a heat flux sensor in monitoring fouling, Proceedings of Fouling and Cleaning in Food Processing, University of Cambridge (Cambridge, UK), Belmar-Beiny, M.T., Fryer, P.J., Eds.; 1994, 230-241.

13. Lohr, K.; Rose, J.L. Ultrasonic guided wave and acoustic impact methods for pipes fouling detection. J. Food Eng. 2003, 56, 315-324.

14. Miyawaki, O.; Sato, Y.; Yano, T.; Ito, K.; Saeki, Y. Fundamental aspect of viscosity monitoring by the hot wire technique. J. Food Sci. 1990, 55 (3), 854-857.

15. Passos, E.F.; Monteiro, P.S.; Oliviera, R.C.; Martins, J.G.O.; Alves, H.G.; Brandao, S.C.C. Predicting the cutting time of coagulating milk for cheese production using a heated thermistor. J. Food Sci. 1999, 64 (5), 879-882.

16. Payne, F.A.; Hicks, C.L.; Pao-Sheng, S. Predicting optimal cutting time of coagulated milk using diffuse reflectance. J. Dairy Sci. 1993, 76, 48-61.

17. Payne, F.A. Fiber optic diffuse reflectance sensor-an analytical sensor for cheesemaking, Proceedings of the Food Processing Automation III Conference, Florida. Am. Soc. Agri. Eng. 1994, 280-288.

18. Shariaty-Niassar, M.; Hozawa, M.; Tsukada, T. Development of probe for thermal conductivity measurement of food materials under heated and pressurized conditions. J. Food Eng. 2000, 43, 133-139.

19. Shimada, K.; Sakai, Y.; Nagamatsu, K.; Hori, T.; Hayashi R. Gel-setting and gel melting temperatures of aqueous gelatin solutions under high pressure measured by hotwire method. Biosci. Biotechnol. Biochem. 1996, 60 (8), 1349-1350.

20. Tavman, I.H.; Tavman, S. Measurement of thermal conductivity of dairy products. J. Food Eng. 1999, 41, 109-114.

21. Truong, T.; Anema, S.; Kirkpatrick, K.; Chen, H. The use of a heat flux sensor for in-line monitoring of fouling of nonheated surfaces. Food Bioproducts Process. 2002, 80 (4), 260-269.
22. Withers, P.M. Ultrasonic, acoustic and optical techniques for the non-invasive detection of fouling in food processing equipment. Trends Food Sci. Technol. 1996, 7, 293-298.

23. Duffau, C.; Grilot, J.M.; Navarro, J.M.; Vidil, R. L'encrassement dans échangeurs: Description, prévention et remèdes. Eds. GRETh, 1991.

24. Janknecht, P.; Melo, L. Online biofilm monitoring, Rev. Environ. Sci. Bio/Technol. 2003, 2, 269-283.

25. Prakash, S.; Datta, N.; Deeth, H. Methods of detecting fouling caused by heating of milk. Food Rev. Int. 2005, 21, 267-293.

26. Tamachkiarowa, A.; Flemming, H.C. Optical fiber sensor for biofouling monitoring. In Understanding Heat Exchanger Fouling and Its Mitigation; Bott, T.R. Ed.; Begell House: New York, 1999; 165, 343-347.

27. Schaule, G., Moschnitschka, D., Schulte, S., Tamachkiarow, A., Flemming, H.-C. Biofilm growth in response to various concentrations of biodegradable material in drinking water. Wat. Sci. Technol. 2007, 55 (8-9), 191-195; In the 6th IWA International Specialty Conference on Biofilm Systems, Sep 24-27, 2006; Amsterdam, Netherlands.

28. Chen, X.D.; Li, D.X.Y.; Lin, S.X.Q.; Ozkan, N. On-line fouling/cleaning detection by measuring electric resistance-equipment development and application to milk fouling detection and chemical cleaning monitoring. J. Food Eng. 2004, 61, 181-189.

29. Lahoucine, C.O.; Khellaf, A. Periodic method: Correction for thermocouple and simultaneous estimation of thermal conductivity and thermal diffusivity. Rev. Sci. Instrum. 2004, 75 (7), 2356-2361.

30. Fukai, J.; Nogami, H.; Ohtani, S. Simultaneous estimation of thermophysical properties by periodic hot-wire heating methods. Exp. Therm. Fluid Sci. 1991, 4, 198-204.

31. Gatecel, J.; Weill, G. Appareillage de mesure de la conductivité thermique des semi-conducteurs. II. La méthode d'Angstrom. Le journal de physique et le Radium 1962, 6 (23), 95-101.

32. Strub, F.; Castaing-Lasvignottes, J.; Strub, M.; Pons, M.; Monchoux, F. Second law analyse of periodic heat conduction through a wall. Int. J. Therm. Sci. 2005, 44, 1154-1160.

33. Crattelet, J.; Auret, L.; Debreyne, P.; Esteve, D.; Fillaudeau, L. Investigation of steady and unsteady thermal regimes to monitor fouling in industrial processes. In Proceeding of 8th World Congress of Chemical Engineering, Montréal, Quebec, Canada, L0122, ISBN:0-920804-44-6, Eds. Canadian Society of Chemical Engineering, 2009.

34. Ghnimi, S.; Debreyne, P.; Fillaudeau, L. Fouling monitoring during ohmic heating of dairy products with a cell jet. In Proceeding of 8th World Congress of Chemical Engineering, Montréal, Quebec, Canada. L0899, ISBN: 0-920804-44-6, Eds. Canadian Society of Chemical Engineering, 2009.

35. Fillaudeau, L.; Debreyne, P.; Cardenas, R.; Korolzuck, J. Method and system for measuring and examining reactor fouling. Inst. Nat. Rech. Agro. (FR) (2007), WO2006FR 5042420060510.

36. Saikhwan, P.; Geddert, T.; Augustin, W.; Scholl, S.; Paterson, W.R.; Wilson, D.I. Effect of surface treatment on cleaning of a model food soil. Surf. Coatings Technol. 2006, 201 (3-4), 943-951.
57
58
59
60
61
62
6 64 65 